\title{
Who Am I: Considerations for Adolescent Development During A Pandemic
}

\author{
Shirin Khazvand", Tennisha N. Riley, MacKenzie P. Whitener, Tamika C.B. Zapolski
}

Indiana University Purdue University Indianapolis, Tennisha N. Riley, Indiana University, United States.

\begin{abstract}
Article Details
Article Type: Short Communication

Received date: $08^{\text {th }}$ May, 2021

Accepted date: $24^{\text {th }}$ May, 2021

Published date: $06^{\text {th }}$ Jun, 2021

"Corresponding Author: Shirin Khazvand, Indiana University Purdue University Indianapolis, Tennisha N. Riley, Indiana University, United States. E-mail: skhazvan@iu.edu

Citation: Khazvand, S., Riley, T.N., Whitener, M.P., \& Zapolski, T.C.B. (2021). Who am I: Considerations For adolescent development during a pandemic. J Ment Health Soc Behav 3(2):143. https://doi.org/10.33790/jmhsb1100143

Copyright: $\mathbb{C} 2021$, This is an open-access article distributed under the terms of the Creative Commons Attribution License $\underline{4.0}$, which permits unrestricted use, distribution, and reproduction in any medium, provided the original author and source are credited.
\end{abstract}

\section{Adolescent Identity Development}

Adolescence is a unique time in which cognitive, affective, and social abilities are at critical periods of development. The result is the discovery of "Who Am I?" or adolescent identity development. Identity development during adolescence includes determining one's values and creating meaning in life, as well as integrating how one is viewed by others and identifying contradictions among these perspectives. By developing an identity that integrates various features of their sense of self, adolescents can better interpret their life experiences, therefore improving their general well-being and health [1]. There are several aspects of adolescent identity development, including participation in sociocultural contexts such as home, school, or work, internal and psychological processes of exploring aspects of identity, and social group membership [2].

These aspects are centered on interactions with others, which are critical to how adolescents evaluate the ways they relate to the world around them [3]. For example, an adolescent might explore aspects of their identity by engaging in specific media or events that fit their self-perspective while also drawing them closer to a particular social group. However, it is the "trying-on" of identity aspects and the perspectives of parents, teachers, and peers that help identity take shape. Given the role others play in adolescent identity development, it is important for adolescents to be involved in activities and groups that allow for the exploration and cultivation of a strong identity.

\section{Ethnic-Racial Identity}

When discussing adolescent identity development, we cannot go without examining ethnic-racial identity development in the context of a racialized society. Ethnic-racial identity is a developmental process where ethnic minority youth explore their ethnicity and race while forming an attachment to their ethnic-racial group [4, 5]. The U.S. Census Bureau estimates that by the end of 2020 youth from ethnic-racial minority backgrounds will be half of the population under age 18. Aside from growth in population, it is vital to consider identity development for adolescents of color because of the unique experiences they face in navigating society as the minority in a Whitemajority dominant culture. In particular, racial-ethnic discrimination has consistently been shown to increase the risk of negative health outcomes [6]. Thus, adolescents' race and ethnicity add a unique layer within identity development that warrants consideration. Research has found ethnic-racial identity to be a protective factor linked to resiliency, higher academic achievement, school engagement, selfesteem, and increased mental and physical health among adolescents of color who have experienced adversity, including racial and ethnic discrimination and its consequences as an extra hurdle for minority youth in addition to navigating other issues during adolescence [4].
Conversely, confusion, uncertainty, and anxiety about racial identity have been tied to negative outcomes, such as reduced school engagement. However, the evidence overwhelmingly suggests that when adolescents of color hold positive racial-ethnic identities, it has positive effects among African American/Black, Latino, Indigenous, Asian American and Pacific Islander youth.

\section{COVID-19: Challenges to Adolescent Identity Development}

Adolescents are forming their identity all while facing potential risks (peer rejection, family conflict, and school failure), though these risks never included a global pandemic. Identity development for adolescents during the COVID-19 pandemic is undoubtedly different from the traditional ways we believe youth develop a sense of self. Interactions with others helps to support the process of exploring social roles, selecting friend groups that match their developing identity, and balancing responsibilities while transitioning to adulthood [7]. The COVID-19 pandemic has shifted these processes that require interactions with others. Social distancing requirements mean smaller peer groups and an inability to introduce new adolescents into those groups. Peers serve as a reflector for understanding which parts of an adolescents' identity fit into group and social norms [8]. Additionally, adolescents may be taking on new responsibilities that influence their social transition into adulthood such as caregiving for ill family members or younger siblings or financial responsibilities as a result of the economic impact of the pandemic. Given the changes to adolescents' social context, particularly within the school setting (e.g., closures of school, distance learning, hybrid schedules, cancellation of sports activities), there are new challenges to fostering positive adolescent identity development.

\section{Adolescents' Strategies for Coping During a Pandemic}

Despite the challenges, youth have found creative ways to explore identity, find meaning, and maintain their connections with their peers in safe ways such as through online platforms [9]. In our work with students in the Midwest, we found that social media has aided in maintaining important relationships outside of school. Many adolescents are also utilizing text messaging and video chat apps to stay in touch with peer groups. Indeed, the current research points to the use of technology, particularly during the pandemic, as a tool to help adolescents both stay connected with peers and family as well as enhance their education [10]. However, there are risks to this coping strategy [11]. Excessive technology use can result in more stress and anxiety due to social comparison or online bullying, and so it might be helpful to focus on how technology is used and what adolescents 
are doing online [12]. Encouraging beneficial use of technology to spend time with family (e.g., interacting with parents or siblings, video calling, working side by side), connecting with peers, and continuing their schoolwork has been associated with better mental health [10]. These types of connections will highlight the availability of support to adolescents at a time in which they may feel especially isolated and stressed.

One way in which technology has served as a potential useful strategy is in the context of racial-ethnic minority youth development. Alongside the effect of the COVID-19 pandemic on adolescent development, remains the country's events centering around discrimination, police brutality, and the Black Lives Matter movement--all of which have disproportionately affected adolescents of color. Despite this, adolescents have engaged in activism like those who organized protests in Houston, Texas (Katy 4 Justice) after being disappointed by their community lack of activism in response to police brutality and racism. These issues have resulted in the involvement of the youngest generation of activists [13]. Activism through use of technology may create the opportunity for exploring ethnic-racial identity and working towards resolution in which there is a clear benefit to adolescent development [14].

In summary, adolescence is a critical time when youth are cultivating their values, purpose, and identity. These pursuits are typically done through activities at school and interactions with peers; however, the COVID-19 pandemic has created challenges affecting social interactions due to school closures and social distancing recommendations. Fortunately, youth have been creative in engaging in some of these activities through social media platforms and activism. Adult figures in adolescents' lives can also support these efforts by creating space for adolescents to understand the impact of the pandemic on their lives and aid in the exploration of plans for the future. Emphasizing connections between the present and future can help make potential identities more accessible and less abstract to youth, especially in low-income communities with less access to future-oriented resources [1]. In time, the pandemic will end, but until then, we all can do our part to help adolescents adjust and continue to achieve developmental milestones, including identity development. After all, today's students are tomorrow's leaders, and it is our responsibility to prepare them for the next chapter.

Competing interests: The authors of this paper declare no competing interests.

\section{References}

1. Schwartz, S. J., \& Petrova, M. (2018). Fostering healthy identity development in adolescence. Nature Human Behaviour, 2(2), 110-111.

2. Verhoeven, M., Poorthuis, A. M. G., \& Volman, M. (2019). The role of school in adolescents' identity development A literature review. Educational Psychology Review, 31(1), 35-63. https:// doi-org.proxy.ulib.uits.iu.edu/10.1007/s10648-018-9457-3

3. Dahl, R. E., Allen, N. B., Wilbrecht, L., \& Suleiman, A. B. (2018). Importance of investing in adolescence from a developmental science perspective. Nature, 554(7693), 441-450.

4. Rivas, D. D., Seaton, E. K., Markstrom, C., Quintana, S., Syed, M., Lee, R. M., Schwartz, S. J., Umaña, T. A. J., French, S., \& Yip, T. (2014). Ethnic and racial identity in adolescence: Implications for psychosocial, academic, and health outcomes. Child Development, 85(1), 40-57. https://doi-org.proxy.ulib. uits.iu.edu/10.1111/cdev.12200

5. Cross, F. L., Hoffman, A. J., Constante, K., \& Rivas-Drake, D. (2018). Ethnic-racial identity content and the development of depressive symptoms among Latino adolescents. Development and Psychopathology, 30(5), 1557-1569.
6. Benner, A. D., Wang, Y., Shen, Y., Boyle, A. E., Polk, R., \& Cheng, Y.-P. (2018). Racial/ethnic discrimination and wellbeing during adolescence: A meta-analytic review. American Psychologist, 73(7), 855-883. https://doi.org/10.1037/ amp0000204.supp (Supplemental)

7. Collins, W. A., \& Steinberg, L. (2006). Adolescent Development in Interpersonal Context. In N. Eisenberg, W. Damon, \& R. M. Lerner (Eds.), Handbook of child psychology: Social, emotional, and personality development (p. 1003-1067).

8. Rivas, D. D., Seaton, E. K., Markstrom, C., Quintana, S., Syed, M., Lee, R. M., Schwartz, S. J., Umaña, T. A. J., French, S., \& Yip, T. (2014). Ethnic and racial identity in adolescence: Implications for psychosocial, academic, and health outcomes. Child Development, 85(1), 40-57. https://doi-org.proxy.ulib. uits.iu.edu/10.1111/cdev.12200.

9. Pancani, L., Marinucci, M., Aureli, N., \& Riva, P. (2020). Forced social isolation and mental health: A study on 1006 Italians under COVID-19 quarantine. Retrieved from http:// dx.doi.org/10.31234/osf.io/uacf

10. Ellis, W. E., Dumas, T. M., \& Forbes, L. M. (2020). Physically isolated but socially connected: Psychological adjustment and stress among adolescents during the initial COVID-19 crisis. Canadian Journal of Behavioural Science / Revue Canadienne Des Sciences Du Comportement, 52(3), 177-187. https://doiorg.proxy.ulib.uits.iu.edu/10.1037/cbs0000215

11. Garfin, D. R., Silver, C. R., \& Holman, A. E. (2020). The novel coronavirus (COVID-19) outbreak: Amplification of public health consequences by media exposure. Health Psychology, 39, 355-357. http://dx .doi.org/10.1037/hea0000875

12. Orben, A., \& Przybylski, A. K. (2019). Screens, teens, and psychological well-being: evidence from three time-use-diary studies. Psychological Science, 30(5), 682-696.

13. Zaveri, M. (2020, July) 'I Need People to Hear My Voice': Teens Protest Racism. New York Times. Retrieved from https:// www.nytimes.com/2020/06/23/us/teens-protest-black-livesmatter.html

14. Umaña-Taylor, A. J., Quintana, S. M., Lee, R. M., Cross, W. E., Jr, Rivas-Drake, D., Schwartz, S. J., Syed, M., Yip, T., Seaton, E., \& Ethnic and Racial Identity in the 21st Century Study Group (2014). Ethnic and racial identity during adolescence and into young adulthood: an integrated conceptualization. Child Development, 85(1), 21-39. https://doi.org/10.1111/cdev.12196 